\title{
Dracula as a Lovesick Monster, Iconology of the PFM's Rock Opera
}

\author{
Andrea Del Castello \\ AT Studio-School of Music, Sulmona, Italy
}

\begin{abstract}
Playbills, covers, and logo of an opera often reflect the meanings of the drama. This paper focuses on above mentioned issues with reference to Dracula, the rock opera of Italian band PFM (Premiata Forneria Marconi), explaining how every visual aspects (also considering scenography and costumes) are closely linked to libretto and music to show the consistency among the different facets of the opera production. In this procedure, graphic artists and designers confirm their knowledge, but apart from this awareness, there are some symptoms of an unconscious creativity as much coherent. As a result, this study aims to show how the management of the biggest colossal in the history of rock opera tries-constantly torn between art and advertising - to attract a potential audience by means of the iconography both of the composers and of the most famous vampire in the world.
\end{abstract}

Keywords: PFM, rock opera, Dracula, music iconology

\section{Introduction}

Contemporary works-compared with the remote ones—offer different possibilities to music iconography. Their aim is not only to give information about the history of musical instruments, performance practices or sceneries, because those are data that we can easy check out in person or acquire by other sources, but rather to reach conclusion about the history of culture and iconology too. In fact, when we analyse a source of the 21 st century, probably we will touch it and interview its author or in any case the persons that have a relationship with it.

This paper is about popular music. In this branch the studies of iconography are very important, because the promotional strategies of the world market of music are really influenced by images.

Precisely the author will concentrate on the iconographic aspects of the PFM's (Premiata Forneria Marconi) rock opera Dracula, relative to the logo, to the covers of the various discographic products, to the playbills and to the promotional poster of the disc, also analysing the relationship between the representation both of the composers and the protagonist of the opera, adding some reference about the scenography and the costumes.

\section{PFM's Dracula}

This opera is a colossal without precedent: The producer David Zard invested about seven million euros on it. The shows began at the Gran Teatro in Rome on the fourth of March 2006 with a 1000 square metre stage, 260 costumes, 30 dancers, 14 actors, 150 persons of technical and managerial staffs.

\footnotetext{
Andrea Del Castello, bachelor, musicologist, scholar of music iconography, AT Studio-School of Music.
} 
The libretto was written by Vincenzo Incenzo, based on Bram Stoker's romance Dracula, written in 1897. But the main point of reference, by the explicit will of the PFM, was Francis Ford Coppola's film Bram Stoker's Dracula, directed in 1992.

The protagonist of this story expresses a strong, erotic magnetism, described by a psychological introspection. Actually the PFM overturns the most well-known image of the Count of Transylvania: a pitiless monster, desirous of blood. In fact now the character denotes a big pathos because of an interior tragedy that he lives in a heart-rending way.

Furthermore Incenzo's lyrics exalt the relationship between the protagonist that symbolises darkness and people who would like to reach the spiritual light of salvation. But they ineluctably prostrate themselves to the hidden yearning of their materiality, showing the impossibility of a splitting between Good and Evil.

Anyway, love is the main theme of the opera, the most carrying away strength, the only one that can overlook Death, in opposition to the works that deny eternal love: Man returns to the usual aim and pursues his feeling forever, sacrificing himself, making wicked gestures and twisted, spiritual fights against himself.

So Love is the real motor of the plot and it defines the development of a story that progresses between hyperbolical trepidations and delightful, coloured scenographic symbols; between hard rock atmospheres and pale strokes of suffused pianism; between tearing apart solistic arias and impetuous choristic sections.

The plot begins more or less on the same wavelength as the historical tradition of this subject, but the end is significantly different, because Dracula dies while he is waiting for the sunrise with Mina. In this situation he represents both the redemption's sacrifice and an extreme gesture of love: to see the dawn at least once with his lover.

\section{The Logo}

In this opera there are a lot of antinomic couples: Good/evil, life/death, possible/impossible, past/present, light/darkness, and nightmare/reality.

Franco Mussida, PFM guitarist, explains how the band transposed this duplicity to the music by means of contrasts:

You can easily obtain musical contrasts, but you can hardly make them homogeneous. We added orchestra and choirs to the rock line-up: this sonority favours the reach of contrast atmosphere, but also obliges us to pay attention, not to recreate the usual stereotypes. We also added electronic sounds: you must have every colour in your paint-brush. (Del Castello, 2005)

Well, looking at the logo (see Figure 1), we can point out an antinomic couple, formed by the dynamic sense in opposite directions that the two most important letters play: the " $\mathrm{D}$ " and the " $\mathrm{C}$ ". The lines that portray those letters absolutely tend to two opposite poles: the " $\mathrm{D}$ " to the left and the " $\mathrm{C}$ " to the right.

But the librettist Vincenzo Incenzo states in the correspondence with the journalist Donato Zoppo:

Dracula is not the renewed version of the brawl between Good and Evil, but rather its aim is to induce the spectator to think that Good and Evil are very close, or better still they love each other [...] Dracula is two lips of an only wound. He is the hidden side of human nature, the Good and the Evil that only apparently fight each other (Zoppo, 2006, p. 241).

In fact, a more careful analysis points out that the chiasmus formed by two intersected lines: The "D" and the "C" are just built on those ones (see Figure 2), as a representation of the most classical contradiction of the 
opposite poles that attract each other: "due labbra della stessa ferita [...] il Bene e il Male sono indivisibili (Two lips of an only wound [...] The Good and the Evil are indivisible)" (Incenzo, 2005, p. 16).

In spite of all that, we can see another antinomic couple: approach/sending away.

Moreover there is a more intricate intersection of converging lines: Every stroke of every letter seems to be an extension projected by the ideal directions of the "D"'s upper and lower edge tangents (see Figure 3).

So there is a total coherence among lyrics, music and iconographic aspects.

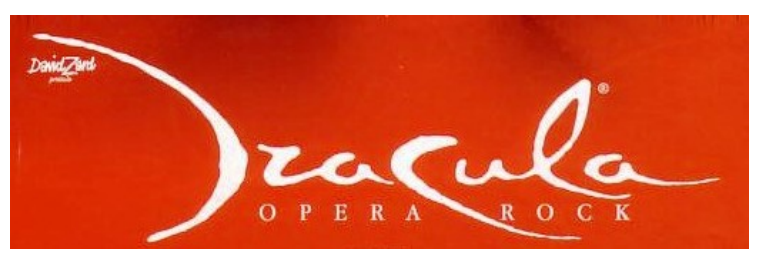

Figure 1. The logo. Source: Booklet.

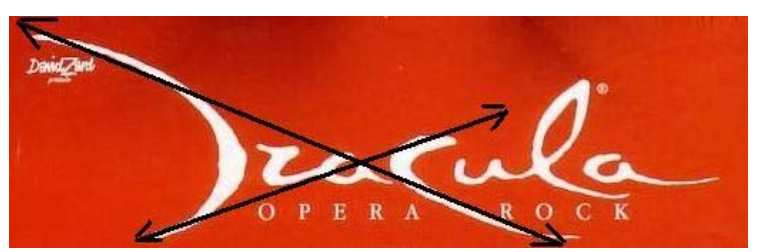

Figure 2. The chiasmus in the logo. Source: Booklet.

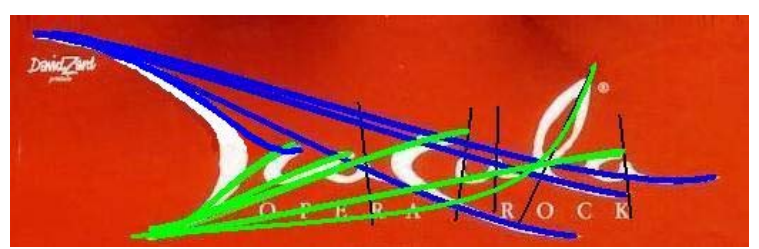

Figure 3. Intersection of converging lines. Source: Booklet.

The designer of the logo is Federico Romanazzo. This is a private conversation between him and the author:

ADC: Did you read the book and listen to the opera before starting your work?

FR: Sure, before the realization of the logo I watched Coppola's film and listened to the PFM's opera, even if it was still without an orchestra. And some years ago I read Stoker's book too.

ADC: Did you create the logo liberally or did someone impose anything on you?

FR: No production elements imposed anything on me.

$\mathrm{AD}$ : According to me, your logo reflects the PFM's opera: an antinomic couple formed by the " $\mathrm{D}$ " and the "C", but built on intersected lines, that is "the Good and the Evil are indivisible". In spite of all that we can consecrate another, antinomic couple: approach/sending away.

FR: (he smiles) Well, the original idea was Dracula giving up his bad role: the birth of light. In fact the wedding in the final scene is dominated by the golden colour of the costumes, more lights and an infinity of reflections, that are, the symbols of the ransomed love, a monster that turns into a good being. Actually I had an initial idea for the logo: lightning rockets from the darkness. Then I directed my mind to the logo you know: Mauro Genovesi made the "D" with his paint-brush and I decided to use the same line to make the "C", turning it upside down.

Subsequently, I began paying big attention to the balance: a so domineering "D" could unbalance the logo, but the "C" on her part should not be too big. All the rest turns around those two letters. Anyway we had to aim the balance, also considering the myriad of uses of this logo: newspapers, playbills, covers et cetera. But the logo had to be visible and recognizable too, whether big or small, oblique, horizontal or vertical and above all it had to be adaptable in every context.

ADC: In this whole harmony of curves, the " $\mathrm{L}$ " is an edge. 
FR: Yes, the drawing of the logo is very dynamic; on the one hand it seems natural, but on the other hand-the case of the "L"-quite artificial. Initially the "L" was very feminine (see Figure 4), then I opted for a harder line, more "rock", more coherent with the music that it represents.

(continues... ) (personal communication, September, 18th, 2007)

Well, Romanazzo unwillingly generates another antinomic couple: naturalness/artificiality.

Instead, regarding the balance, we notice that the external letters ("D" and "A") and the central one ("C") are separated from the internal couples ("RA" and "UL"): Those divisions create totally symmetric spaces (see Figure 5).

The last remark concerns the mirror-like aspect of the two principal letters. In Stoker's work the mirror plays a considerable role: It is the means that Jonathan uses to be sure of the abnormality of his host. Dracula throws it away, indicating it as a cursed object, a horrid trifle of human vanity.

So, the symmetric dances that recreate the reflections of reality represent the mirror in the choreography.

Instead, in the iconography this peculiarity is represented by the mirror-like letters: " $D$ " and " $C$ ".

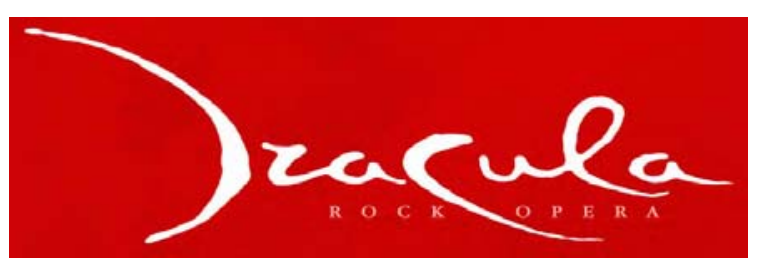

Figure 4. Previous version of the logo. Source: Private archive-Federico Romanazzo.

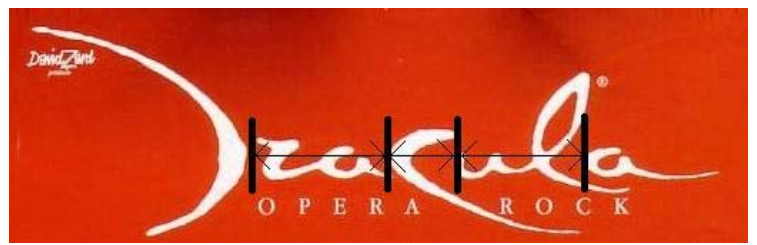

Figure 5. Symmetric spaces in the logo. Source: Booklet.

\section{Playbills and Dracula's Eyes}

"È l'occhio la finestra dell'anima (The eye is the window of the soul)" Tito Schipa Jr sang in Vieni sole from his Orfeo 9, the first Italian rock opera, the first ever performed in the world. In fact the composer-protagonist decided to represent his disguised face with open eyes drawn on the closed eyelids, even for the cover of the long playing (see Figure 6).

I planned the cover on a strong image of the film, the open eyes painted on the closed eyelids. I thought of an animation based upon that image, alternating the first and the third page of the double long-playing (closed/open and then open/open). (Schipa , 2005, p. 154) (see Figure 7)

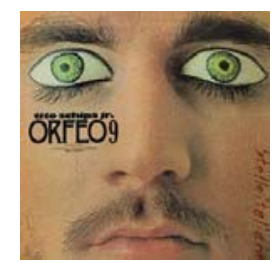

Figure 6. Orfeo 9. Source: Album cover. 


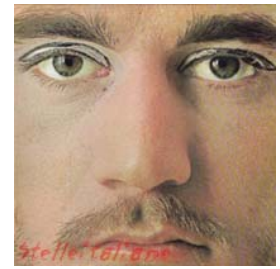

Figure 7. Orfeo 9. Source: Internal cover.

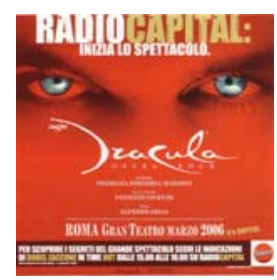

Figure 8. Handbill. Source: Radio Capital Archive.

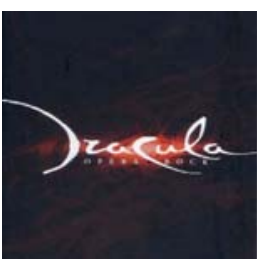

Figure 9. Dracula (case, full version-2 cd). Source: Cover.

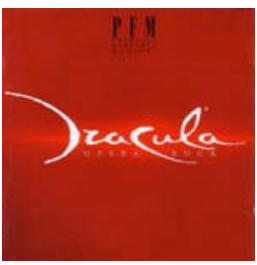

Figure 10. Dracula (highlights—1 cd). Source: Cover.

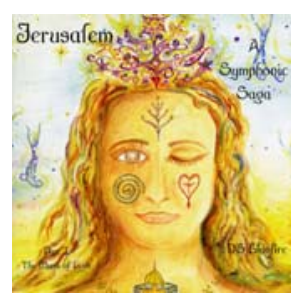

Figure 11. Jerusalem . Source: Album cover.

Well, it is noteworthy that the visual material of the two most important Italian rock operas is marked by the communicative power of the eyes: the cover of the disc for Orfeo 9 as well as the playbills, handbills and pamphlets for Dracula.

In addition, we can also notice the formal parallelism (see Figures $6,7, \& 8$ ). Also the cover of the rock opera-or better still—the symphonic saga Jerusalem composed by DS Lionfire represents the contrast open eye/closed eye (see Figure 11). The deepening of the matter in relation to the iconography in art history would be lengthy and would lead off topic.

However, Romanazzo denies a direct influence from Orfeo 9. 
Here is the second part of the interview.

ADC: Why did you decide to represent the eyes?

FR: The logo is not sufficient for communication, particularly for a new opera. We wanted something else to stand out: we tried with the image of a hand, then a mouth with a part of a tooth outside, but we did not want to use stereotypes.

At last we chose the eyes, trying to give them a strong sense of deepness, allowing them to stand out in the red background: it was disturbing enough, it referred to the concept we wanted to explain, but also we did not want this concept to be a predominating element of communication. After all they were not the eyes of our Dracula, we only wanted to give an idea.

ADC: Why are they blue?

FR: Initially they had to be black in contrast to the red, whereas a white reflection of light had to give life to the iris. Then David Zard had the idea to make them blue (see Figure 8).

ADC: And why is there red colour around the iris? Do they refer to the Stoker character?

FR: It is only a chromatic choice. At the start we wanted to base the communication on the black colour (as we did for the case) (see Figure 9), then we opted for blood red (as we did for the disc) (see Figure 10) and then chose white for the title to get a strong light. (personal communication, September, 18th, 2007)

\section{The Poster of the Disc and the PFM's Gazes}

Regarding the disc and its cover, when Romanazzo and his staff started working on the communication, there was still no material of the opera. For instance, the photos of the costumes (see Figures 12, 13, \& 14) were made only nine days before the first dressed rehearsal. So play-bills of subsequent performances in Milano e Verona, represent the protagonist (see Figures 15 \& 16). These are not Romanazzo's works.

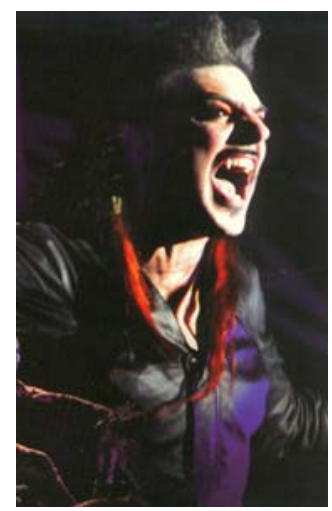

Figure 12. Vincenzo Matteucci.. Source: Photograph by Laura Camia.

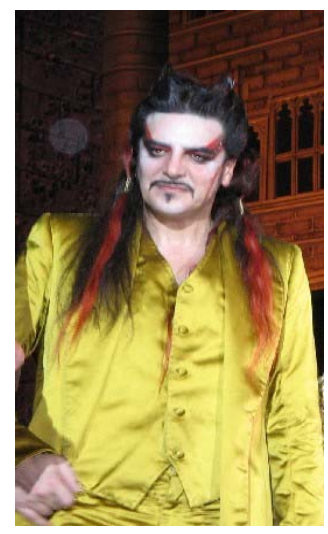

Figure 13. Vincenzo Matteucci. Source: Photograph by Laura Camia. 


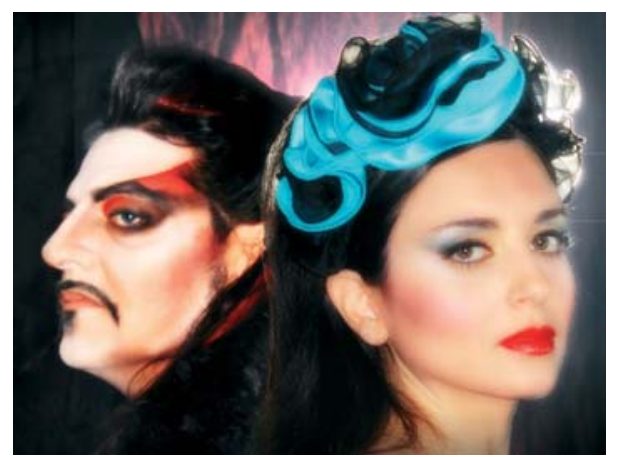

Figure 14. Vincenzo Matteucci and Sabrina De Siena. Source: Photograph by Laura Camia.

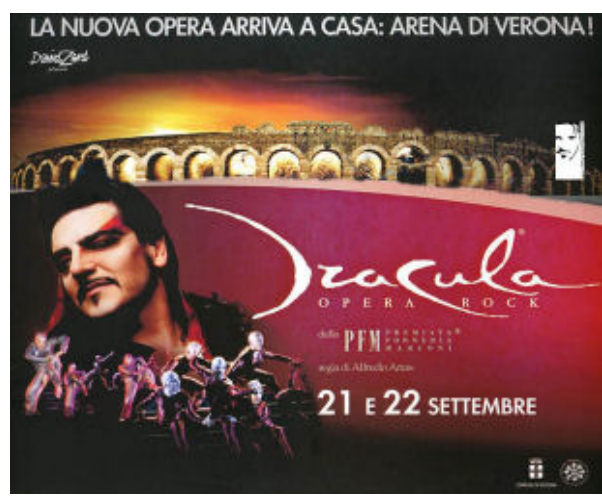

Figure 15. Play-bill, Verona, September 21st-22nd, 2006. Source: David Zard production

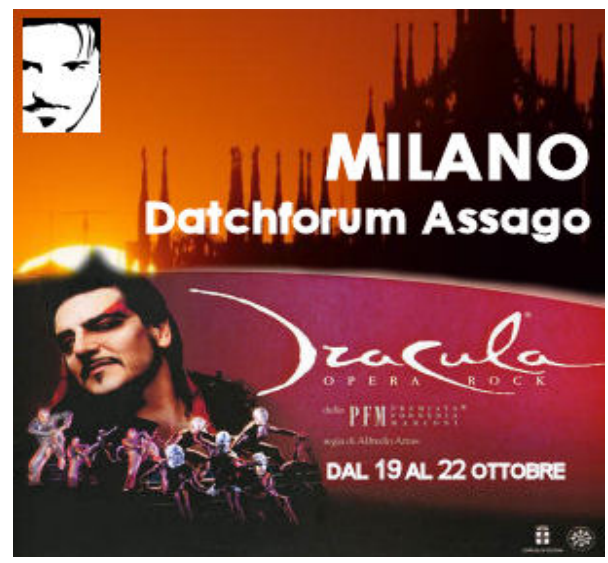

Figure 16. Play-bill, Milano, October 21st-22nd, 2006. Source: David Zard production.

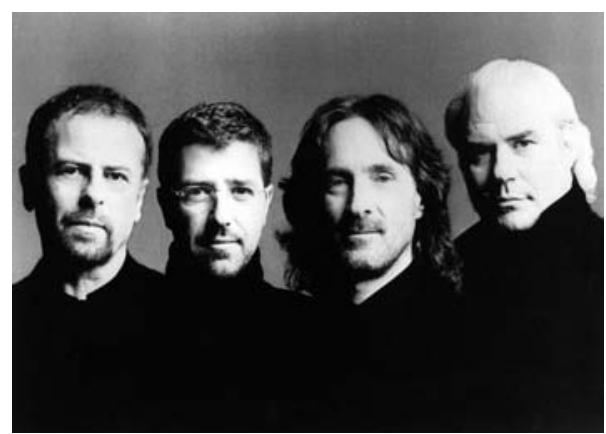

Figure 17. Premiata Forneria Marconi. Source: www.pfmpfm.it official website. 


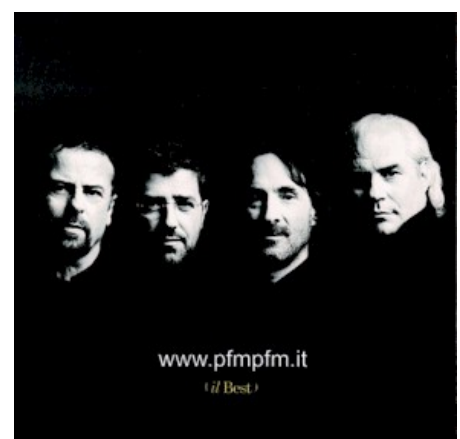

Figure 18. www.pfmpfm.it (il best). Source: Album cover.

In a first phase, the production asked Romanazzo to promote this product as a PFM's disc, so he overlapped a photo of the musicians (see Figure 17) to the logo. At that time they changed their mind and decided to promote it as the disc of the opera: So only the logo remained on the cover (see Figure 10), but the solution with the image of the band was chosen for the promotional poster (see Figure 19).

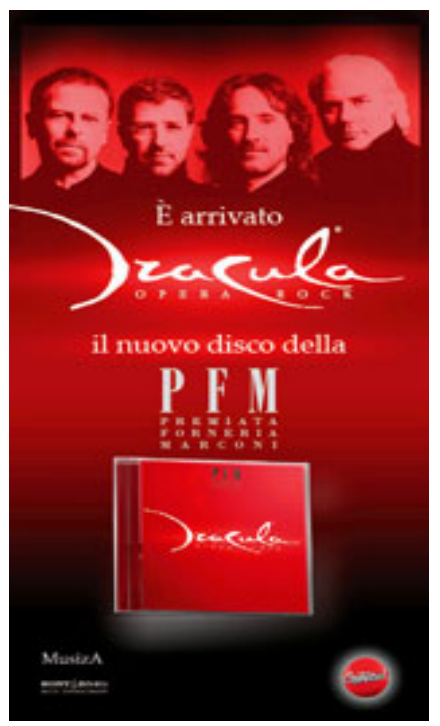

Figure 19, Poster. Source: Musiza.

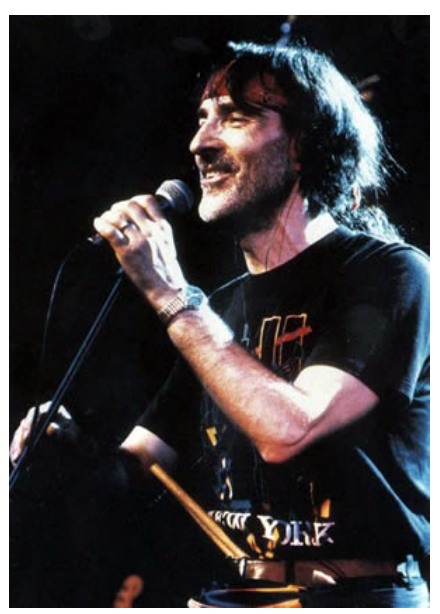

Figure 20. Franz Di Cioccio. Source: www.pfmpfm.it official website. 
Well, why did Romanazzo's staff choose just that photo? Of course, it was the most suitable one: It was an image already well-known and "digested" by fans and other people, as it has been already used as the cover for the double long playing www.pfmpfm.it (il best) released in 1998 (see Figure 18). Besides, the album title is a website promotion.

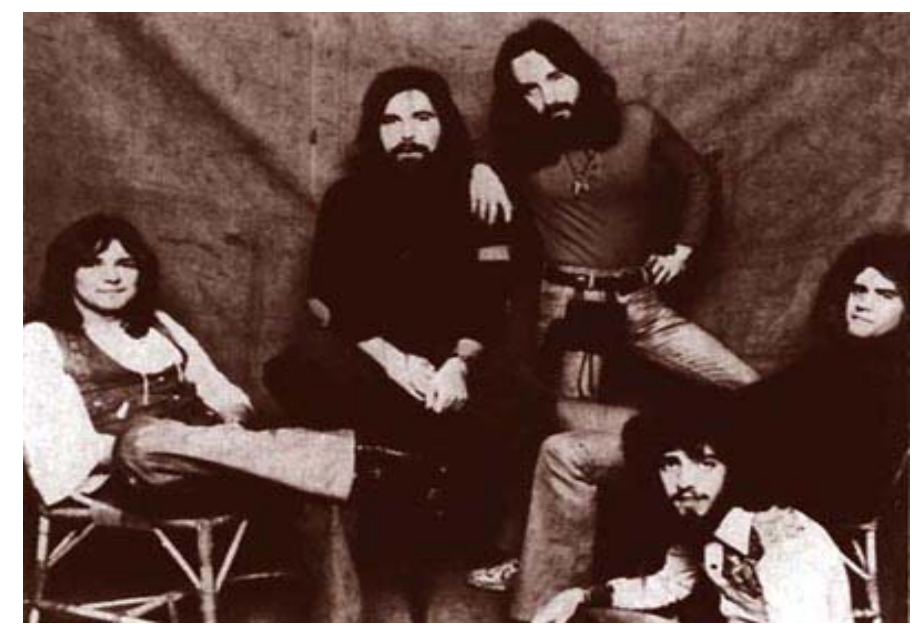

Figure 21, Premiata Forneria Marconi. Source: www.pfmpfm.it official website.

Another reason is the parallelism with the playbill and the handbill, as the gaze of the musicians is pointed to the referent-observer.

But the most important reason concerns the new look, the new image that the band wants to communicate: an idea of cultured, elegant composers for a refined audience.

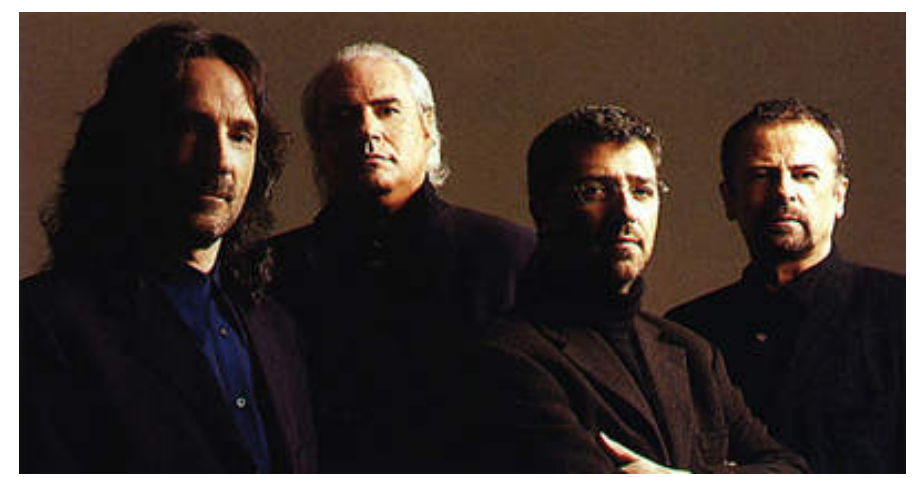

Figure 22, Premiata Forneria Marconi. Source: D\&D Concert

So diametrically opposite to the freak spirit of the youthful years (see Figures $20 \& 21$ ), the image that the PFM communicates in the 21 st century (see Figure 22) reflects their aged characteristic, however hidden in the first phase of their career: a great culture that goes beyond its extreme, incommensurable technical skill. Well, the band has revealed this new look since the 90's and particularly with this anthological album that—as Zoppo suggested "dispels every doubt: It is the manifesto of the new PFM" (Zoppo, 2006, p. 209).

\section{References}

Del Castello, A. (2005). Dracula, l'opera rock della PFM. Intervista a Franco Mussida (Dracula, the PFM's rock opera. Interview to Franco Mussida). Retrieved from http:// www.musicalnews.com 
Del Castello, A. (2006a). Cresce l'attesa e fervono i preparativi e perla prima dell'opera rock Dracula (The anticipation grows and preparations are going on everywhere for the rock opera Dracula). Retrieved from http://www.musicalnews.com

Del Castello, A. (2006b). Il debutto di Dracula della PFM al Gran Teatro (PFM's Dracula début at the Gran Teatro). Retrieved from http://www.musicalnews.com

Di Cioccio, F. (1996). Due volte nella vita (Twice in a life) (2nd ed. (2009). Milano: Aereostella). Milano: Mondatori.

Incenzo, V. (2005). Dracula. Roma: Musiza Edizioni Musicali.

Oleari, A., \& Stefanel, R. (2012). Storia di un minuto (History of a minute). Milano: Aereostella.

Schipa, T. J. (2005). Orfeo 9. Il making. Civitella Val di Chiana-Arezzo: Zona.

Stoker, B. (1897). Dracula. London.

Zoppo, D. (2006). Premiata Forneria Marconi. Roma: Editori Riuniti. 